\title{
Lives saved from malaria prevention in Africa- evidence to sustain cost-effective gains
}

\author{
Eline $L$ Korenromp $p^{1,2}$
}

\begin{abstract}
Lives saved have become a standard metric to express health benefits across interventions and diseases. Recent estimates of malaria-attributable under-five deaths prevented using the Lives Saved tool (LiST), extrapolating effectiveness estimates from community-randomized trials of scale-up of insecticide-treated nets (ITNs) in the 1990s, confirm the substantial impact and good cost-effectiveness that ITNs have achieved in high-endemic subSaharan Africa. An even higher cost-effectiveness would likely have been found if the modelling had included the additional indirect mortality impact of ITNs on preventing deaths from other common child illnesses, to which malaria contributes as a risk factor.

As conventional ITNs are being replaced by long-lasting insecticidal nets and scale-up is expanded to target universal coverage for full, all-age populations at risk, enhanced transmission reduction may-above certain thresholds-enhance the mortality impact beyond that observed in the trials of the 1990s. On the other hand, lives saved by ITNs might fall if improved malaria case management with artemisinin-based combination therapy averts the deaths that ITNs would otherwise prevent.

Validation and updating of LiST's simple assumption of a universal, fixed coverage-to-mortality-reduction ratio will require enhanced national programme and impact monitoring and evaluation. Key indicators for time trend analysis include malaria-related mortality from population-based surveys and vital registration, vector control and treatment coverage from surveys, and parasitologically-confirmed malaria cases and deaths recorded in health facilities. Indispensable is triangulation with dynamic transmission models, fitted to long-term trend data on vector, parasite and human populations over successive phases of malaria control and elimination.

Sound, locally optimized budget allocation including on monitoring and evaluation priorities will benefit much if policy makers and programme planners use planning tools such as LiST - even when predictions are less certain than often understood. The ultimate success of LiST for supporting malaria prevention may be to prove its linear predictions less and less relevant.
\end{abstract}

Keywords: Malaria/economics, Malaria/prevention and control, Mortality, Child, Programme impact, Programme evaluation, Financing, Health resources, Investments, Africa

\section{Background}

Ongoing scale-up of malaria control in an era of leveling funds for health requires that investments are justified in terms of their impact and value for money [1]. The Roll Back Malaria partnership, United Nations (through the Millennium Development Goals) and World Health Assembly share a target of reducing malaria deaths by 75\% between 2000 and 2015; updated Roll Back Malaria

\footnotetext{
Correspondence: eline.korenromp@theglobalfund.org

${ }^{1}$ Global Fund to Fight AIDS, Tuberculosis and Malaria, Vernier, Geneva $\mathrm{CH}-$

1214, Switzerland

Full list of author information is available at the end of the article
}

targets of May 2011 include an even more ambitious reduction to near-zero malaria deaths by 2015 [2]. Achieving these targets depends critically on the success of malaria prevention, in particular the provision of insecticide-treated nets (ITNs) in sub-Saharan Africa, the region covering $91 \%$ of global malaria deaths. Encouragingly, from 2000 to 2010 nine (out of 43) malaria-endemic African countries, as well as 35 (out of 53) Asian countries with ongoing transmission achieved a more than $50 \%$ reduction in notified malaria cases [2].

\section{Biomed Central}

(c) 2012 Korenromp; licensee BioMed Central Ltd. This is an Open Access article distributed under the terms of the Creative Commons Attribution License (http://creativecommons.org/licenses/by/2.0), which permits unrestricted use, distribution, and reproduction in any medium, provided the original work is properly cited. 


\section{Discussion}

Lives saved have become a standard metric to express these benefits across interventions and diseases [3-8]. The study by Eisele and colleagues [9] was long-awaited to confirm the large child health gains realized by malaria vector control, primarily ITNs. Across 36 African countries, ITN scale-up is estimated to have reduced malaria mortality deaths by $24 \%$ in year 2010 , and to have prevented 842,800 under-five deaths between 2001 and 2010 . These estimates translate into a cost of US\$ 2,770 per life saved or US\$ 111 per DALY averted, when compared to the counterfactual of malaria mortality levels as in 2000, when ITN coverage was negligible in most countries.

The Lives Saved Tool (a.k.a. LiST) used by Eisele and colleagues is a suitable mortality projection model, that has the advantage of considering the impact of malaria interventions in the context of multiple key child health interventions, and the full envelope of child deaths from all causes [10-12].

The authors qualify their malaria impact estimates as conservative, which is probably correct despite several uncertainties; in any case the presented cost-effectiveness ratios are somewhat below those published earlier $[13,14]$.

First, lives saved were evaluated within an envelope of malaria-attributable deaths, estimated at $17 \%$ of all-cause deaths in children 1-59 months in the year 2000 [15]. In the context of estimating child survival gains across multiple disease control programs, this approach avoids the conceptual problem that lives saved across all interventions would add up to more than the total actual deaths in the population. However, in reality the impact of malaria prevention extends beyond direct malaria-attributable deaths, since malaria acts as a risk factor by causing chronic anaemia, malnutrition and generally weakening child health $[16,17]$. The cluster-randomized ITN trials that provided the basis for ITN efficacy estimates suggest that this indirect effect may be at least as large as the direct effect within malaria-attributable deaths; which is also why all-cause under-five mortality had-rightly-been the primary effectiveness measure in these trials [18].

Second, the ITN trials, reaching a near-universal (80$100 \%$ ) household possession of ITNs, estimated effectiveness at a stable $17 \%$ reduction in all-cause mortality among children 1-59 months, or 5.5 per 1,000 child-years [18]. Re-analysing three of these five trials, Eisele and colleagues translated this effectiveness into a fixed 55\% reduction in malaria-attributable deaths in the same age group [19]. However, the trial sites differed markedly in baseline malaria transmission intensity (entomological inoculation rates ranging from $<10$ to $>300$ ), all-cause under-five mortality levels (13 to 52 per 1,000 child-years) and the proportion of post-neonatal child deaths due to malaria (36-46\% in three trials). It is unclear how all three of these effectiveness measures could be constant across the five sites at the same time-and, by extrapolation, some 15 years later across 36 countries, several of which have since markedly reduced under-five mortality and/or malaria burden [10,20-23].

A third uncertainty is how ITN effectiveness plays out at coverage levels different from the near-universal household possession achieved in the trials. Across the 36 countries now analysed, household ownership ranged from $3.5 \%$ to $94 \%$ in 2010 [9]. LiST assumes simple linearity, but effectiveness in the lowest-coverage countries may be disproportionally lower if dynamic transmission effects would only kick in at high coverage [24]. Conversely: Is a $55 \%$ reduction in malaria-attributable mortality, without additional indirect effects on other-cause deaths, a valid maximum effectiveness for universal net coverage? The latter is the more important question looking forward, for two reasons: First, long-lasting insecticidal nets (LLINs) are replacing conventional ITNs that required retreatment to remain effective. Second, since 2007, the WHO recommends personal protection for the full population at risk instead of just children under-five and pregnant women, resulting in increasing numbers of households owning and using not just one but several ITNs [2].

Further re-analysis of data from the 1990s trials will not improve certainty here. More up-to-date reassurance comes from a recent ecological analysis of household surveys across 22 countries. At ITN ownership levels ranging from $1 \%$ to $54 \%$ (over 2001-2009), ITN household ownership reduced all-cause post-neonatal under-five mortality by $24 \%$ (when adjusted for socioeconomic determinants and coverage of other key child health services), more than the $17 \%$ in the cluster-randomized trials [25]. While this survey-based analysis could not estimate the corresponding absolute mortality reduction, it suggests that ITN impact might still be fairly stable at 5.5 deaths prevented per 1,000 child-years of protection, despite the secular trend of falling child mortality.

Enhanced validation of ITN/LLIN effectiveness assumptions would require model fitting to individual settings that scaled-up ITN coverage and measured all-cause and malaria-attributable mortality trends, in the absence of change in other child health interventions. This situation is-fortunately-becoming rarer, as countries scale-up vector control alongside improved malaria treatment [26,27], and as part of broader health systems strengthening. A recent 'validation' study by the same authors found that LiST-predictions fitted child mortality reductions within the $95 \%$ CI of empirical observations across two of the ITN trials and two observational studies. However, of these individual sites two had a 'fit' $33-35 \%$ too high, and two a 'fit' $22-25 \%$ too low [28]-suggesting that the malaria 
community remains far from a good understanding of ITN's protective efficacy and its determinants across sites.

Validation against recent programme scale-up and mortality trends will furthermore help to monitor whether mortality patterns as of 2000 (adjusted only for population growth) remain the best counterfactual. Even if ITN usage stopped altogether, malaria-related mortality may not resurge to levels as high as in 2000, since child deaths from other major-interacting-causes such as measles, pneumonia and HIV have fallen since [29,30]. Also is malaria treatment with ACT, by lowering case fatality rates, reducing the envelope of potentially fatal malaria deaths that ITNs would prevent [24]. Finally, indoor residual spraying (IRS) is compounding the impact of ITNs, although precise estimates of IRS impact at a regional level are still lacking due to missing data on population-level coverage from some countries.

Next ambitions should focus on enhancing mortality measurement, and on better understanding the impact of vector control in settings of varying endemicity, mortality and anti-malarial treatment patterns. This requires better population-based data on the effective coverage of ACTbased treatment [31] and IRS, and of impact indicators such as parasite infection and anaemia in children [32]. As the coverage of parasitological diagnosis (through microscopy and rapid diagnostic tests) is scaled-up, routine statistics on hospitalizations and in-hospital deaths from parasitologically confirmed malaria will also become an increasingly reliable source $[2,23,27,33]$. For mortality, the long-term goal for all countries should be to achieve complete and accurate vital registration, classifying causes of death with the International Coding of Deaths system version 10 (ICD-10) [34]. Where nation-wide vital registration is not feasible, sample vital registration or demographic surveillance using verbal autopsy to establish causes of death can be a cost-effective interim approach $[35,36]$.

Synthesizing new insights from improved impact data requires a very different type of models, simulating interactions between vector, parasite and human populations over successive phases of malaria control and elimination $[24,37]$. Dynamic transmission modelling, fitted in detail to selected sites, is indispensable to refine assumptions for simplified health sector planning tools like LiST.

Meanwhile, LiST remains useful to guide short-term strategic planning and M\&E priorities in endemic countries, notably reinforcing international recommendations to measure child service coverage and impact indicators through nationally representative household surveys. The pending incorporation of ACT-based treatment [31] will improve LiST's value for programme budgeting-by illustrating the efficiencies expected by shifting allocations from presumptive (symptom-based) treatment that inevitably wastes-scarce-ACT courses on patients with non-malarial fevers, to increased diagnosis and prevention.

\section{Conclusions}

Malaria elimination is becoming a tempting goal even for several currently endemic African countries. But recent gains remain fragile in view of evolving drug and insecticide resistance, malaria's epidemic nature, and the challenge to sustain programme funding despite many competing development priorities that are all (very) cost-effective [2]. Sound, locally optimized budget allocations will benefit much if policy makers and programme planners use simple tools as LiST-even when predictions are much less certain than often understood. The ultimate success of LiST for supporting malaria prevention may be to prove its linear predictions less and less relevant.

\section{Disclaimer}

My views do not necessarily represent the decisions, policy or views of the Global Fund to Fight AIDS, Tuberculosis and Malaria. I declare that I have no conflicts of interest.

\section{Acknowledgements}

I would like to thank Dr. Colin Mathers and Dr. Chris Dye (World Health Organization) for comments on a draft of the commentary.

\section{Author details}

'Global Fund to Fight AIDS, Tuberculosis and Malaria, Vernier, Geneva CH1214, Switzerland. '2Department of Public Health, Erasmus MC, University Medical Center Rotterdam, Rotterdam, Netherlands.

Received: 16 December 2011 Accepted: 28 March 2012 Published: 28 March 2012

\section{References}

1. The Global Fund to Fight AIDS Tuberculosis and Malaria: Improving value for money in Global Fund supported programs. The Global Fund to Fight AIDS, Tuberculosis and Malaria, Third Replenishment (2011-2013). Geneva 2010 [http://www.theglobalfund.org/en/donors/replenishments/ thirdreplenishment1stmeeting/documents/ ] .

2. World Health Organization: World Malaria Report 2011 Geneva; 2011 [http:// www.who.int/malaria/world_malaria_report_2011/en/index.html].

3. Komatsu R, Korenromp EL, Low-Beer D, Watt C, Dye C, Steketee RW, Nahlen BL, Lyerla R, Garcia-Calleja JM, Cutler J, Schwartländer B: Lives saved by Global Fund-supported HIV/AIDS, tuberculosis and malaria programs: estimation approach and results between 2003 and end-2007. BMC Infect Dis 2010, 10:109.

4. United States of America state government: Implementation of the Global Health Initiative: consultation document \& ANNEX A: Global Health Initiative Goals, 2009 - 2014 Washington DC; 2009 [http://www.pepfar.gov/ documents/organization/136504.pdf].

5. Walensky RP, Kuritzkes DR: The impact of the President's Emergency Plan for AIDS Relief (PEPfAR) beyond HIV and why it remains essential. Clin Infect Dis 2010, 50:272-275.

6. Glaziou P, Floyd K, Korenromp EL, Sismanidis B, Bierrenbach A, Williams B, Atun R, Raviglione M: Lives saved by tuberculosis control and prospects for achieving the 2015 global target for reductions in tuberculosis mortality. Bull World Health Organ 2011, 89:573-582.

7. Mahy M, Stover J, Kiragu K, Hayashi C, Akwara P, Luo C, Stanecki K, Ekpini R, Shaffer N: What will it take to achieve virtual elimination of mother-to- 
child transmission of HIV? An assessment of current progress and future needs. Sex Transm Infect 2010, 86(Suppl 2):ii48-ii55.

8. Stover J, Korenromp EL, Blakley M, Viisainen K, Komatsu R, Atun R: Longterm costs and health impact of continued Global Fund support for antiretroviral therapy. PLoS One 2011, doi:10.1371/journal.pone.0021048.

9. Eisele T, Larsen DA, Walker N, Cibulskis R, Yukich JO, Zikusooka CM, Steketee RW: Estimates of child deaths prevented from malaria prevention scale-up in Africa 2001-2010. Malar J 2012, 11(1):93.

10. Hazel E, Gilroy K, Friberg I, Black RE, Bryce J, Jones G: Comparing modelled to measured mortality reductions: applying the Lives Saved Tool to evaluation data from the Accelerated Child Survival Programme in West Africa. Int J Epidemiol 2010, 39(Suppl 1):i32-i39.

11. Ricca J, Prosnitz D, Perry H, Edward A, Morrow M, Ernst P, Ryan L: Comparing estimates of child mortality reduction modelled in LiST with pregnancy history survey data for a community-based NGO project in Mozambique. BMC Publ Health 2011, 11(Suppl 3):S35.

12. Bryce J, Friberg IK, Kraushaar D, Nsona H, Afenyadu GY, Nare N, KyeiFaried S, Walker N: LiST as a catalyst in program planning: experiences from Burkina Faso, Ghana and Malawi. Int J Epidemiol 2010, 39(Suppl 1): i40-i47.

13. Yukich JO, Lengeler C, Tediosi F, Brown N, Mulligan JA, Chavasse D, Stevens W, Justino J, Conteh L, Maharaj R, Erskine M, Mueller DH, Wiseman V, Ghebremeskel T, Zerom M, Goodman C, McGuire D, Urrutia JM, Sakho F, Hanson K, Sharp B: Costs and consequences of large-scale vector control for malaria. Malar J 2008, 7:258

14. White MT, Conteh L, Cibulskis R, Ghani AC: Costs and cost-effectiveness of malaria control interventions - a systematic review. Malar J 2011, 10:337.

15. Rowe AK, Rowe SY, Snow RW, Korenromp EL, Schellenberg JA, Stein C, Nahlen BL, Bryce J, Black RE, Steketee RW: The burden of malaria mortality among African children in the year 2000. Int J Epidemiol 2006, 35:691-704.

16. Snow RW, Korenromp EL, Gouws E: Paediatric anaemia and mortality in Africa: Plasmodium falciparu malaria as a cause or risk? Am J Trop Hyg Med 2004, 7(Suppl 2):16-24.

17. Scott JA, Berkley JA, Mwangi I, Ochola L, Uyoga S, Macharia A, Ndila C, Lowe BS, Mwarumba S, Bauni E, Marsh K, Williams TN: Relation between falciparum malaria and bacteraemia in Kenyan children: a populationbased, case-control study and a longitudinal study. Lancet 2011, 378:1316-1323.

18. Lengeler $C:$ Insecticide-treated bed nets and curtains for preventing malaria (Cochrane review). Cochrane Database Syst Rev John Wiley \& Sons, Ltd; 2004, CD000363[http://onlinelibrary.wiley.com/doi/10.1002/14651858. CD000363.pub2/pdf ].

19. Eisele TP, Larsen D, Steketee R: Protective efficacy of interventions for preventing malaria mortality in children in Plasmodium falciparu endemic areas/Modeling the Impact of Scaling up Interventions for Malaria. Int J Epid 2010, 39(Suppl 1):i88-i101.

20. Masanja H, de Savigny D, Smithson P, Schellenberg J, John T, Mbuya C, Upunda G, Boerma T, Victora C, Smith T, Mshinda H: Child survival gains in Tanzania: analysis of data from demographic and health surveys. Lancet 2008, 371:1276-1283.

21. Nakamura H, Ikeda N, Stickley A, Mori R, Shibuya K: Achieving MDG 4 in sub-Saharan Africa: what has contributed to the accelerated child mortality decline in Ghana? PLOS One 2011, 6:e17774.

22. D'Acremont V, Lengeler C, Genton B: Reduction in the proportion of fevers associated with Plasmodium falciparu parasitaemia in Africa: a systematic review. Malar J 2010, 9:240.

23. Cibulskis R, Aregawi M, Williams R, Otten O, Dye C: Worldwide incidence of malaria in 2009: estimates, time trends, and a critique of methods. PLoS Med 2011, 8:e1001142.

24. Smith DL, Hay SI, Noor AM, Snow RW: Predicting changing malaria risk after expanded insecticide-treated net coverage in Africa. Trends Parasitol 2009, 25:511-516.

25. Lim SS, Fullman N, Stokes A, Ravishankar N, Masiye F, Murray CJ, Gakidou E: Net benefits: a multicountry analysis of observational data examining associations between insecticide-treated mosquito nets and health outcomes. PLoS Med 2011, 8:e1001091.

26. Otten M, Aregawi M, Were W, Karema C, Medin A, Bekele W, Jima D, Gausi K, Komatsu R, Korenromp E, Low-Beer D, Grabowsky M: Initial evidence of reduction of malaria cases and deaths in Rwanda and Ethiopia due to rapid scale-up of malaria prevention and treatment. Malar J 2009, 8:14.
27. Aregawi M, Ali AS, Al-mafazy A, Molteni F, Warsame M, Katikiti S, Njau RJ, Komatsu R, Korenromp EL, Hosseini M, Low-Beer D, Bjorkman A, D'Alessandro U, Coosemans M, Otten M: Reductions in malaria and anemia case and death burden to hospitals following scale-up of malaria control in Zanzibar, 1999-2008. Malar J 2011, 10:46.

28. Larsen DA, Friberg IK, Eisele TP: Comparison of Lives Saved Tool model child mortality estimates against measured data from vector control studies in sub-Saharan Africa. BMC Publ Health 2011, 11(Suppl 3):S34.

29. World Health Organization: Dept of Health Statistics and Informatics (Information Evidence and Research cluster): The global burden of disease2004 update Geneva: World Health Organization; 2008.

30. Black RE, Cousens S, Johnson HL, Lawn JE, Rudan I, Bassani DG, Jha P Campbell H, Walker CF, Cibulskis R, Eisele T, Liu L, Mathers C: Global, regional, and national causes of child mortality in 2008: a systematic analysis. Lancet 2010, 375:1969-1987.

31. Thwing J, Eisele TP, Steketee RW: Protective efficacy of malaria case management and intermittent preventive treatment for preventing malaria mortality in children: a systematic review for the Lives Saved Tool. BMC Publ Health 2011, 11(Suppl 3):S14.

32. Korenromp EL, Armstrong-Schellenberg JR, Williams BG, Nahlen BL, Snow RW: Impact of malaria control on childhood anaemia in Africa - a quantitative review. Trop Med Int Health 2004, 9:1050-1065.

33. Thiam S, Thior M, Faye B, Ndiop M, Diouf ML, Diouf MB, Diallo I, Fall FB, Ndiaye JL, Albertini A, Lee E, Jorgensen P, Gaye O, Bell D: Major reduction in anti-malarial drug consumption in Senegal after nation-wide introduction of malaria rapid diagnostic tests. PLoS One 2011, 6:e18419.

34. MDG Africa Steering Group: Achieving the Millennium Development Goals in Africa - Recommendations of the MDG Africa Steering Group The United Nations Department of Public Information, New York City; 2008.

35. Korenromp EL, Bierrenbach AL, Williams BG, Dye C: The measurement and estimation of tuberculosis mortality. Int J Tuberc Lung Dis 2009, 13:283-303.

36. Zachariah R, Mwagomba B, Misinde D, Mandere BC, Bemeyani A, Ginindza T, Cortier H, Bissel K, Jahn A, Harries AD: Vital registration in rural Africa: is there a way forward to report on health targets of the Millennium Development Goals? Trans R Soc Trop Med Hyg 2011, 105:301-309.

37. malERA Consultative Group on Modeling: A research agenda for malaria eradication: modeling. PLoS Med 2011, 8:e1000403.

doi:10.1186/1475-2875-11-94

Cite this article as: Korenromp: Lives saved from malaria prevention in Africa-evidence to sustain cost-effective gains. Malaria Journal 2012 11:94.

\section{Submit your next manuscript to BioMed Central and take full advantage of:}

- Convenient online submission

- Thorough peer review

- No space constraints or color figure charges

- Immediate publication on acceptance

- Inclusion in PubMed, CAS, Scopus and Google Scholar

- Research which is freely available for redistribution 